\title{
Expression of the Potato Leafroll Virus ORF0 Induces Viral-Disease-like Symptoms in Transgenic Potato Plants
}

\author{
Frank van der Wilk ${ }^{1}$, Petra Houterman ${ }^{1}$, Jos Molthoff ${ }^{1}$, Fabienne Hans ${ }^{1,2}$, Ben Dekker ${ }^{3}$, Johannes van \\ den Heuvel', Harm Huttinga ${ }^{1}$, and Rob Goldbach ${ }^{2}$ \\ ${ }^{1}$ DLO Research Institute for Plant Protection (IPO-DLO), P.O. Box 9060, 6700 GW Wageningen, The Neth- \\ erlands; ${ }^{2}$ Wageningen Agricultural University, Department of Virology, P.O. Box 8045, 6700 EM Wagenin- \\ gen, The Netherlands; ${ }^{3}$ MOGEN International NV, Einsteinweg 97, 2333 CB Leiden, The Netherlands \\ Received 30 July 1996. Accepted 4 December 1996.
}

The role of the open reading frame 0 (ORF0) of luteoviruses in the viral infection cycle has not been resolved, although the translation product (p28) of this ORF has been suggested to play a role in host recognition. To investigate the function of the potato leafroll luteovirus (PLRV) p28 protein, transgenic potato plants were produced containing the ORF0. In the lines in which the ORF0 transcripts could be detected by Northern (RNA) analysis, the plants displayed an altered phenotype resembling virus-infected plants. A positive correlation was observed between levels of accumulation of the transgenic transcripts and severity of the phenotypic aberrations observed. In contrast, potato plants transformed with a modified, untranslatable ORF0 sequence were phenotypically indistinguishable from wild-type control plants. These results suggest that the p28 protein is involved in viral symptom expression. Southern blot analysis showed that the transgenic plants that accumulated low levels of ORF0 transcripts detectable only by reverse transcription-polymerase chain reaction, contained methylated ORF0 DNA sequences, indicating down-regulation of the transgene provoked by the putatively unfavorable effects p28 causes in the plant cell.

The genome of potato leafroll virus (PLRV), a species of the genus Luteovirus, consists of a single-stranded, messenger-sense RNA molecule comprising six open reading frames (ORFs) (van der Wilk et al. 1989; Mayo et al. 1989; Keese et al. 1990). The genomic RNA contains a VPg and is encapsidated in an icosahedral particle. The viral capsid is composed of two proteins. The major coat protein is encoded by the ORF3 present in the 3'-half of the genomic RNA. A minor readthrough protein is expressed by translational readthrough of the ORF3 and is believed to be an important aphid transmission determinant of the virus (Brault et al. 1995; Chay et al. 1996; Ziegler-Graff et al. 1996).

Currently, little is known about the role of most of the products of the nonstructural genes of luteoviruses. The ORF2 rep-

Corresponding author: F. van der Wilk

E-mail: F.vanderWilk@ipo.dlo.nl resents the putative viral polymerase gene, since its product

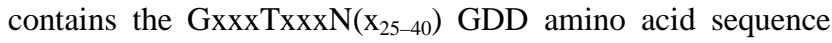
motif, which is conserved in all known RNA-dependent RNA polymerases (Koonin 1991). The ORF1 product contains a protease motif (Bazan and Fletterick 1989; Gorbalenya et al. 1989), but the role of this putative protease in the viral infection cycle is still concealed. The ORF4 product most probably constitutes the viral movement protein, since it has been shown to bind single-stranded nucleic acids (Tacke et al. 1991, 1993) and to be indispensable for systemic infection of plants (Chay et al. 1996). The function of the ORF0 product is still obscure. ORF0 encodes a $28-\mathrm{kDa}$ protein that is highly hydrophobic and shows a weak homology with several membrane-linked proteins (Mayo et al. 1989).

Analysis of the amino acid sequence of PLRV ORF0 has revealed a putative membrane-binding site between residues 21 and 32 (Mayo et al. 1989). The genomic organization of PLRV is very similar to those of the other subgroup II luteoviruses, e.g., beet western yellows virus (BWYV) (Veidt et al. 1988). Comparisons made between the PLRV- and BWYVencoded proteins revealed that all the viral proteins share a high homology in amino acid sequence except for the ORF0s. Although the ORF0s of both viruses are similar in size and position on the genome, the primary structures of their respective products $(\mathrm{p} 28)$ are not recognizably similar. Furthermore, there are no indications that the BWYV ORF0 product is membrane-linked. From an ecological point of view the main difference between the two viruses lies in their host ranges, PLRV being only capable of infecting a limited number of plant species (mostly Solanaceae) (Harrison 1984) and BWYV able to infect many different plant species (Duffus 1972). Since the ORF0 products seem to constitute the main genetic difference between the viruses, it has been suggested that ORF0 plays a role in host recognition (Veidt et al. 1992).

The transformation of plants with viral nonstructural genes is a useful approach to the analysis of an interaction between the virus-encoded proteins and the host plant. To investigate the function of PLRV p28, potato plants were transformed with the ORF0. Plants expressing this ORF0 displayed a viraldisease-like phenotype, indicating that p28 interferes with the metabolism of the plant. 


\section{RESULTS}

\section{Analysis of transgenic potato plants expressing the PLRV ORFO.}

Transgenic potato plants, cv. Désirée, were produced harboring the PLRV ORF0. To this end, a cDNA fragment consisting of the wild-type ORF0 sequence, including the $5^{\prime}$ end of the underlying ORF2, was cloned into a binary transformation vector (Fig. 1A). Transformation of tuber disks was mediated by Agrobacterium tumefaciens. Forty-four independent transformants were obtained.

Eighteen of the produced plant lines were phenotypically dissimilar from the other transformants or from nontransgenic potato plants. Five of these plant lines displayed stunting and deformation of the leaves; these types of aberrations have been observed previously in potato transformations and were probably caused by somaclonal variation during the regeneration process. The other deviant plants displayed yellowing and rolling of the leaves, anthocyan formation in the leaf, and slow and (severely) stunted growth of the plant (Fig. 2). The leaves of these plants were thickened and brittle. The plants displaying the more extreme phenotypic aberrations exhibited slow or impeded root formation both in soil and on medium containing or devoid of kanamycin. Several of the obtained transgenic plants were not able to produce viable tubers. In general, the observed phenotypic aberrations strongly resembled viraldisease-like symptoms. The changes in the phenotypic appearance of the plants were not due to conditions in tissue culture, since plants grown from tubers displayed exactly the same phenotype. The disease-like symptoms developed approximately 7 days after planting or within 3 days after sprouting, and increased with aging of the plants.

The manifestation and extension of the phenotypic aberrations were strongly influenced by the light intensity used to grow the plants. High light intensities induced strong phenotypic aberrations, while at low light intensities phenotypic changes were milder. This is analogous to symptom development of luteovirus-infected plants, in which symptoms are enhanced by elevated light intensities (Rochow 1970; Duffus 1972; Ashby 1984).

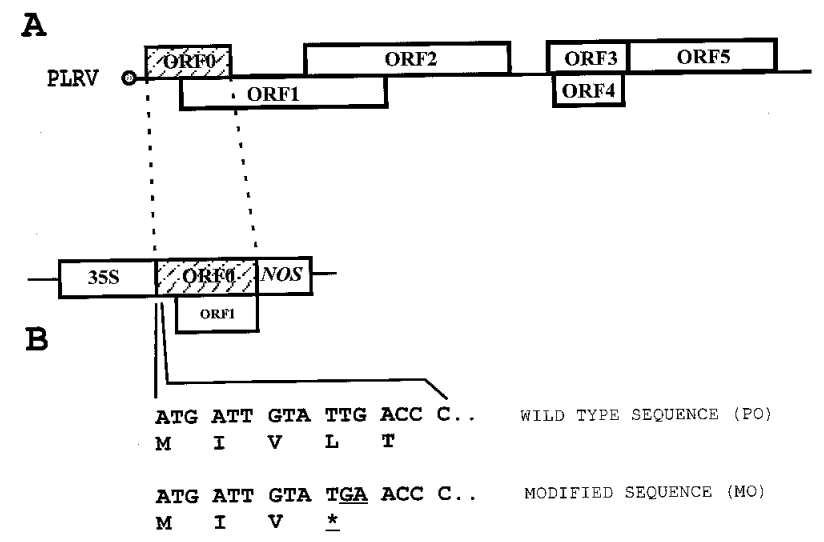

Fig. 1. Schematic representation of the potato leafroll virus (PLRV) genome (A) and construction of the open reading frame 0 (ORF0) plant transformation vectors (B); 35S = cauliflower mosaic virus (CaMV) 35S promoter; nos = nopaline synthase terminator. PO: wild-type ORF0 sequence; MO: modified ORF0 sequence. Modifications are underlined.
The RNA in the transgenic plants was tested by Northern (RNA) blotting to detect the presence of ORF0-specific mRNA (Fig. 3). In 14 of the transgenic plants there were detectable levels of ORF0 mRNA. With the exception of one plant line (PO34), the presence of detectable amounts of ORF0 mRNA in the transgenic potato plants coincided with the presence of virus-like symptoms. This line (PO34) was indistinguishable from nontransgenic potato plants but contained detectable levels of ORF0 mRNA. In all other cases, the severity of the virus-like symptoms was directly correlated with the levels of accumulation of ORF0 transcripts, suggesting that expression of PLRV ORF0 sequences caused the appearance of symptoms similar to those of a PLRV-infected plant.

To determine whether accumulation of ORF0 mRNA had an effect on host mRNA accumulation, the transgenic plants were tested for accumulation of mRNA encoding actin and the small sub-unit of ribulose-biphosphate-carboxylase (rubisco). This analysis revealed that all lines contained comparable amounts of mRNA coding for actin (data not shown), but that the accumulation of rubisco mRNA was strongly inhibited in the plants displaying virus-like symptoms (Fig. 3). In plants showing extreme phenotypic aberrations, accumulation of rubisco mRNA was barely detectable by Northern analysis. These plants were extremely stunted, and the leaves were distorted and ranged in color from yellow to brown.

To verify whether the transgenic plant lines displaying the altered phenotype contained complete, nonmutated ORF0 sequences, polymerase chain reaction (PCR) was carried out with isolated genomic DNA as a template. The 5'terminal primer used in the PCR experiments was identical to a sequence internally located in the cauliflower mosaic virus (CaMV) 35S promoter, while the downstream primer was complementary to the $3^{\prime}$ end of ORF0. PCR performed with genomic DNA isolated from all lines, including those that did and those that did not express ORF0 mRNA, produced DNA fragments of the expected size. Sequence analysis of these PCR products showed that all plants tested contained unaltered copies of the PLRV ORF0 sequence.

\section{Analysis of transgenic and PLRV-infected potato plants for $\mathbf{p} 28$.}

To detect p28, all the transgenic plants and PLRV-infected potato plants were tested in Western blot procedures or in enzyme-linked immunosorbent assays (ELISAs). In the Western blot analysis an antiserum raised against an E. coli expressed p28/GST fusion protein was used and in ELISA antisera were used that had been raised against synthetic peptides. The latter antisera had been shown previously in immunofluorescence experiments to recognize native p28 protein expressed in SF9 insect cells, using the baculovirus expression system (data not shown). The detection limit of the antiserum used in the Western blot procedure was approximately $1 \mathrm{ng}$ of purified GSTp28 protein, while the other antisera exhibited a slightly lower affinity. Since it has been suggested that p28 is membraneassociated (Mayo et al. 1989), several different procedures were examined to isolate $\mathrm{p} 28$ from transgenic or infected plant tissue, including methods specifically designed to isolate membrane-linked proteins (Deom et al. 1990; Martin and Garcia 1991). However, in transgenic and infected plants p28 protein could be detected neither on Western blot nor by ELISA. 
Production and characterization of transgenic plants harboring a modified ORF0 sequence.

Since it was not possible to detect the p28 protein in the transgenic plants it was investigated whether translational expression of PLRV ORF0 initiated the observed viral-diseaselike symptoms. The alternative explanations were that the phenotypic aberrations were caused by the transformation procedure, the underlying $5^{\prime}$-terminal sequence of the ORF2, or the presence of ORF0 RNA sequences themselves. To this end, potato plants (cv. Désirée) were transformed with a modified ORF0 sequence (MO) or with the wild-type sequence $(\mathrm{PO})$ as a control. As shown in Figure 1B, the modified se-
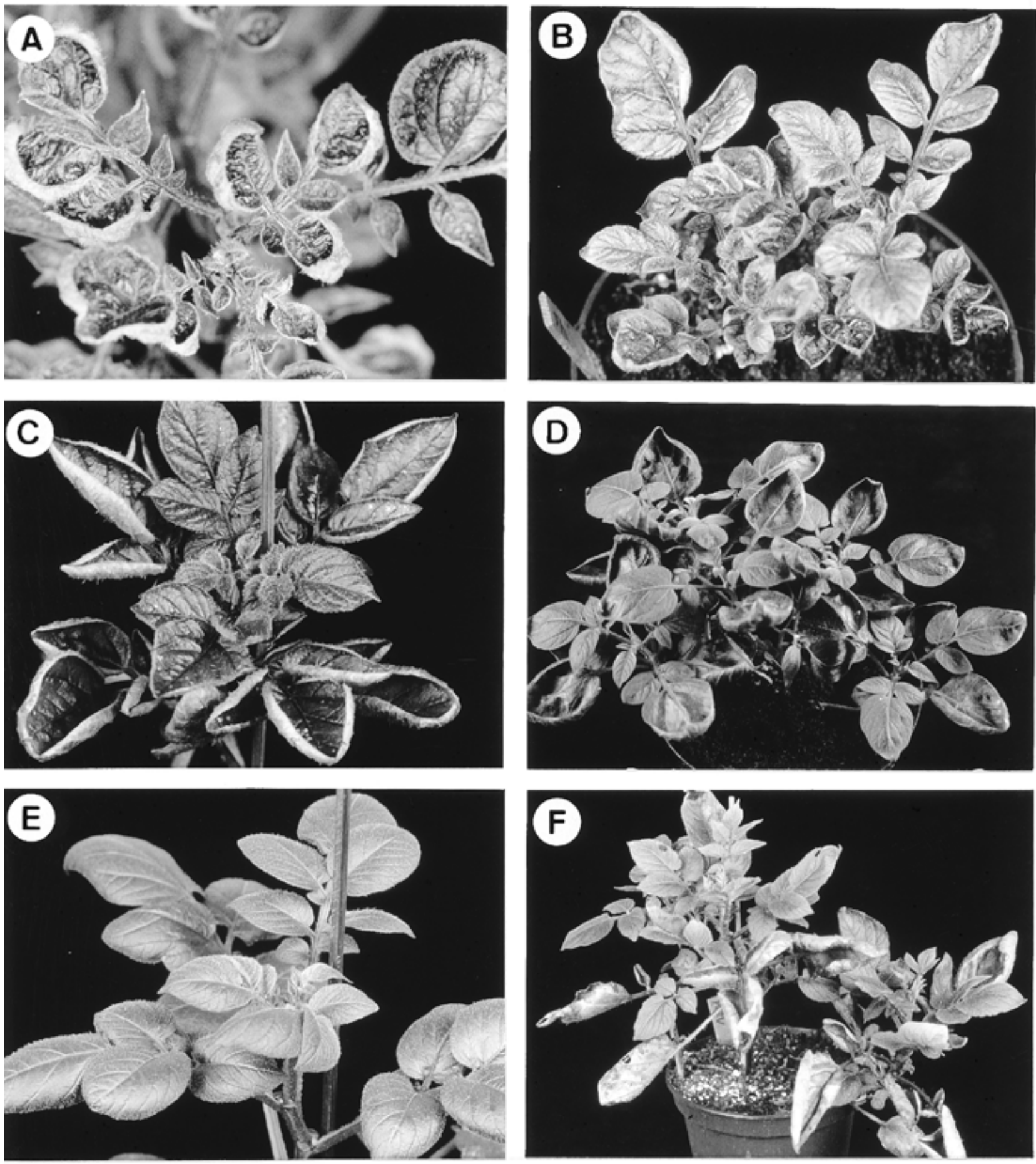

Fig. 2. Phenotypes of potato leafroll virus open reading frame 0 (PLRV ORF0) transgenic potato plants expressing detectable levels of transgenic transcripts. A, B, C, and D, transgenic lines PO4, PO18, PO24, PO134, respectively. E, Wild-type potato plant cv. Désirée. F, Cv. Désirée infected with PLRV. 
quence contained a stop codon (UGA) 6 nucleotides downstream of the start codon, thus blocking the translation of the ORF0 reading frame. The next possible start for translation of the p28 is located at $\mathrm{Met}^{144}$, virtually excluding the possible generation of a truncated $\mathrm{p} 28$ protein.

The MO construct was introduced into 80 independent lines and the PO construct into 25 lines. Regeneration of the MO plants in general took 3 to 9 weeks less than that of the PO plants; all MO lines but 14 were phenotypically similar to wild-type potato. These $14 \mathrm{MO}$ lines displayed stunting and distortion of the leaves. Rolling and yellowing of the leaves and anthocyan formation were never observed. The phenotypic aberration of these MO lines was similar to the phenotype associated with somaclonal variation. Northern blot analysis of 80 transgenic MO plant lines disclosed that $90 \%$ of the examined plants contained detectable levels of ORF0 transcripts.

The results from the transformation experiments with the wild-type ORF0 sequence were comparable to the results from the initial transformation experiment. In total, 25 independent transgenic plant lines were obtained. Only five plant lines accumulated full-length ORF0 transcripts detectable on Northern blot. Two of these plant lines showed severe phenotypic aberrations probably caused by somaclonal variation occurring during the regeneration process. However, two transgenic plant lines displayed the typical viral-disease-like symptoms identical to the earlier observed phenotype.

\section{Southern blot analysis of the transgenic plants.}

The results from the aforementioned experiments indicate that the accumulation of ORF0 transcripts was suppressed in

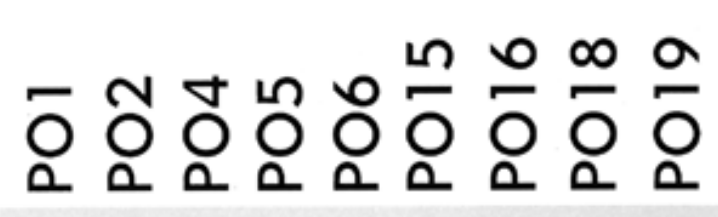

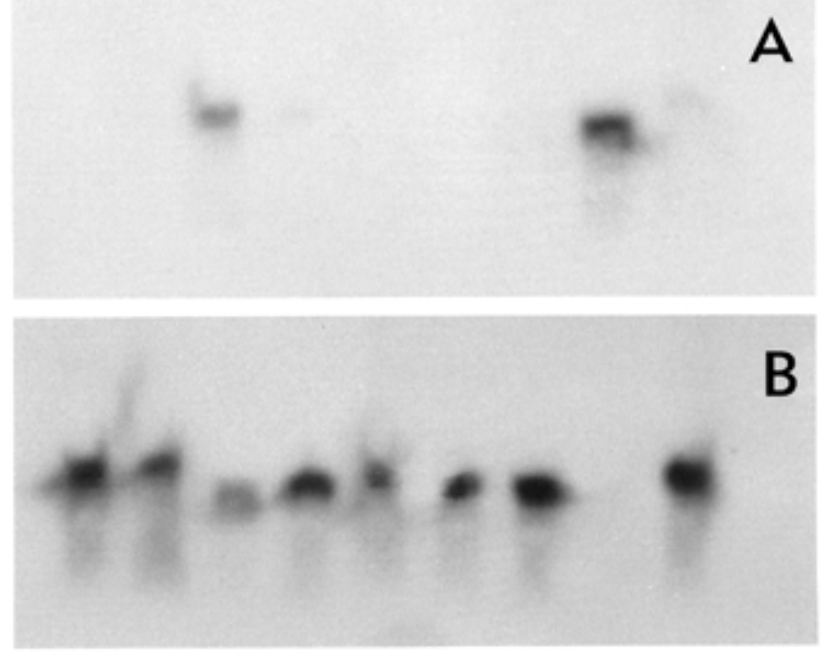

Fig. 3. Northern (RNA) blot analysis of potato leafroll virus open reading frame 0 (PLRV ORF0) transgenic potato plants. Aliquots $(20 \mu \mathrm{g})$ of total plant RNA purified from transgenic leaf material were loaded onto a $1 \%$ agarose gel containing formaldehyde. A, Blot probed with a radiolabeled ORF0 DNA fragment. B, Blot probed with radiolabeled rubisco DNA. the PO plants. Methylation of DNA sequences has been shown to play a role in reduction of the transcription of transgenes (for review see Razin and Cedar 1991). Therefore, Southern blot analysis was carried out to determine whether methylation of the inserted ORF0 sequences played a role in down-regulation of the transcription of the inserted ORF0 construct. To this end, genomic DNA was digested with HindIII and PstI. The restriction endonuclease Pst I in inhibited by the presence of an $N^{6}$-methyladenine or 5-methylcytosine residue in its recognition site. Pst I restriction sites are present both in the $5^{\prime}$-terminal sequence of the ORF0 and in the bordering T-DNA upstream of the $35 \mathrm{~S}$ promoter still inserted in the genome of the plant, while HindIII cleaves immediately after the nos terminator. Digestion of the plant genomic DNA with HindIII and PstI would therefore result in the occurrence of two fragments of approximately 1,300 (Pst I/HindIII) and 850 base pairs (PstI/PstI), unless one of the restriction sites was blocked. As shown in Figure 4, both expected fragments could be detected in the lanes loaded with PstI/HindIIIdigested DNA derived from plants expressing detectable levels of ORF0 transcripts. Non-expressors either did not contain a full-length copy of the ORF0 or a fragment was revealed of approximately $2.2 \mathrm{~kb}$. A fragment of this size could only arise by non-digestion of the ORF0 internal PstI site. However, interpretation of the results was complicated by the presence of smaller fragments possibly caused by deletion of transgene sequences. To verify whether the occurrence of the 2-kb fragment was caused by specific blocking of the ORF0 PstI site and was not due to overall incomplete digestion of the genomic DNAs, the blots were hybridized with a PstI-derived rubisco fragment. Since in all lanes only fragments of the expected sizes (approximately $2 \mathrm{kbp}$ ) were observed, it was concluded that all DNAs were completely digested. From these data it was deduced that the transgene ORF0 sequences were methylated. The copy numbers of the integrated ORF0 constructs, as determined by Southern analysis, were estimated to be between one and three (data not shown).

To determine whether methylation of the transgene sequences completely inhibited transcription, reverse transcription PCR was carried out with primers identical to the $5^{\prime}$ end

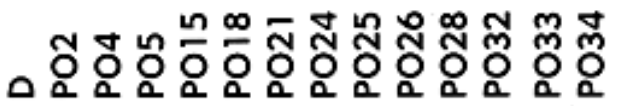

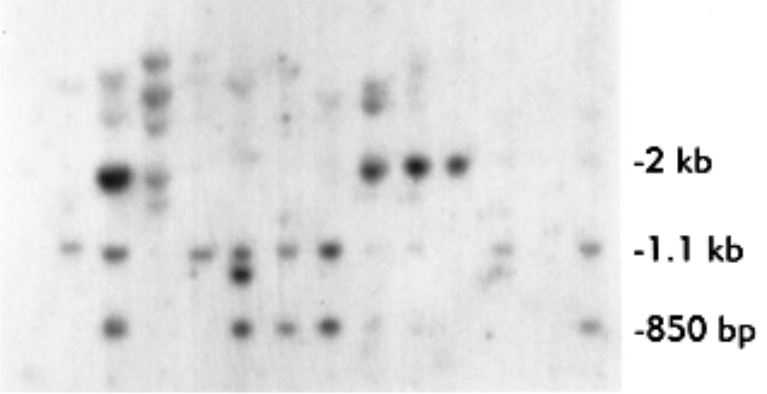

Fig. 4. Southern blot analysis of transgenic potato plants. Aliquots of $(40 \mu \mathrm{g})$ of DNA, purified from transgenic leaf material, and digested with PstI and HindII,I were loaded onto a $1 \%$ agarose gel and subsequently probed with a radiolabeled open reading frame 0 (ORF0) DNA fragment. 
and complementary to the $3^{\prime}$ end of the ORF0. All transgenic plants shown to contain full-length copies by Southern analysis yielded ORF0-related PCR products, indicating that low levels of transcripts were present and that methylation did not completely inhibit transcription.

\section{DISCUSSION}

Except for the structural proteins, little is known about the functions of the putative products of the ORFs present on the genome of PLRV in particular and of luteoviruses in general. It is still obscure which ORF encodes the VPg, and concerning the nonstructural genes only the putative RNA-dependent RNA polymerase (by sequence comparison) and a putative movement protein have been identified (Tacke et al. 1991, 1993; Chay et al. 1996). To gain insight in the function of the non-structural ORF0 of PLRV, we have transformed potato with this sequence. The resulting transgenic (PO) plants that accumulated levels of ORF0 transcripts detectable on Northern blot displayed a phenotype resembling viral-diseased plants. Since transgenic MO plants that expressed a modified, untranslatable ORF0 sequence were phenotypically identical to wild-type potato plants, it is concluded that translational expression of the PLRV ORF0 provoked the observed viraldisease-like symptoms.

Northern blot analysis of the transgenic PO plants revealed that accumulation of mRNA encoding rubisco was impeded. Both the change in phenotype and the decrease in accumulation of rubisco mRNA indicate that expression of the ORF0 interfered with the metabolism in the plant cells. High light intensities used to grow the plants ameliorated the severity of the observed symptom-like phenotype, suggesting that p28 intervenes in the photosynthesis. An alternative explanation is that p28 induces blocking of the transport through the floem, resulting in accumulation of high levels of metabolites in the cell and subsequent suppression of photosynthesis.

Attempts to detect the ORF0 product in transgenic tissues were unsuccessful. p28 has been suggested to be membranelinked (Mayo et al. 1989). However, with procedures reported to be successful for the isolation of viral membrane-bound proteins, p28 could not be detected in either ELISAs or Western blots. These findings coincide with our findings that the detection of p28 is infeasible in PLRV-infected plant tissues and protoplasts (data not shown). Possibly, p28 is rapidly degraded in the plant cell to circumvent a toxic effect imparted by the accumulation of p28 in the cell.

Approximately one third of the obtained transgenic PO plants accumulated levels of ORF0 mRNA detectable in Northern blot procedures. In contrast, $90 \%$ of the MO transgenic potato plants containing the modified, untranslatable ORF0 sequence were shown to accumulate detectable levels of transgenic transcripts. Furthermore, the level of accumulation of transgenic mRNA in plants expressing the wild-type ORF0 was notably lower than in transgenic plants expressing the modified ORF0 sequence. In all experiments, the same binary transformation vector, and thus promoter, was used to express the different ORF0 sequences in plants. Differences in accumulation of mRNA have been shown to be caused by variations in the level of transcription due to methylation of transgenic sequences (for review see Razin and Cedar 1991) or by post-transcriptional degradation of the mRNA (van
Blokland et al. 1994). Southern blot analysis revealed that the plants accumulating low levels of transgenic transcripts contained methylated ORF0 sequences, while in plants expressing high levels of ORF0 transcripts non-methylated transgene DNA was predominant. It has been reported that gene inactivation by methylation is influenced by the copy number of the transferred gene (Linn et al. 1990; Scheid et al. 1991). However, we have not observed a correlation between the estimated transgene copy numbers and methylation. Possibly, the observed suppression of transgene expression by methylation was triggered by the putatively disadvantageous effects p28 causes in the cell.

Previously, it has been reported that expression of the BL1 protein of the geminivirus squash leaf curl virus (SqLCV) (Pascal et al. 1993), the p19 and p22 protein of tomato bushy stunt virus (TBSV) (Scholthof et al. 1995a), and the gene VI product of the pararetrovirus CaMV (Baughman et al. 1988) induced viral-disease-like phenotypes. While expression of CaMV gene VI conveyed viral-disease-like symptoms in nonhost plants but failed to do so in susceptible host plants (Goldberg et al. 1989), expression of SqLCV BL1 and TBSV p19 induced viral-disease-like symptoms in their permissive host, Nicotiana benthamiana. SqLCV is a bipartite, phloemlimited, circular, single-stranded DNA virus, while TBSV is a single-stranded RNA virus. Interestingly, both BL1 and p19 have been identified as movement proteins and have been shown to be important determinants of viral host range properties (Lazarowitz 1991; Ingham and Lazarowitz 1993; Scholthof et al. 1995b), and both SqLCV and TBSV encode two proteins involved in transport of the virus, BR1/ BL1 and $\mathrm{p} 19 / \mathrm{p} 22$, respectively. The function of the PLRV p28 remains an enigma, but it may well be that the protein is involved in movement of the virus in conjunction with the ORF5encoded, 17-kDa protein, analogous to the situation of TBSV and SqLCV.

\section{MATERIALS AND METHODS}

\section{Production of transgenic plants.}

The sequence encoding the PLRV ORF0 was excised from an existing cDNA clone (van der Wilk et al. 1989) employing the PCR. Two ORF0 constructs with different oligonucleotides were synthesized. The first construct (pORF0) was analogous to the wild-type PLRV ORF0 sequence, while the second one (pORFM) contained a stop codon 6 nucleotides downstream of the ORF0 start codon, thus inhibiting translation (Fig. 1B). To facilitate further subcloning, the ORF0 sequences were supplied with BamHI restriction sites located immediately in front of and after the start and stop codons. To exclude the occurrence of possible mutations or deletions the obtained fragments were translated in vitro with the TnT T7 Coupled Reticulocyte Lysate System (Promega, Madison, WI) and sequenced. Subsequently, the fragments were placed between the CaMV 35S-promoter and the nopaline synthase terminator (nos) by ligation in BamHI-digested pMOG181. The resulting plasmids (pMOGORF0 and pMOGORFM) were digested with EcoRI and HindIII and the fragments containing the ORF0 cassette were inserted in the binary vector pMOG402, giving rise to the plasmids $\mathrm{pBPO}$ and $\mathrm{pBMO}$. Transformation of potato plants was done as previously described (Hoekema et al. 1989). Potato tuber disks (cv. Dési- 
rée) were co-cultivated with Agrobacterium tumefaciens LBA4404 harboring pBPO or pBMO. For co-cultivation, 1,000 tuber disks were used in the first experiment and 500 discs in the second. Selection for transformation was done on medium containing kanamycin $(100 \mu \mathrm{g} / \mathrm{ml})$. Kanamycin resistant shoots were cut off and placed onto rooting medium, propagated axenically, and transferred to soil.

\section{Analysis of RNA in transgenic potato plants.}

The transgenic plants were analyzed on Northern blot for expression of ORF0 encoding mRNA. Total RNA was isolated from plant material following the procedure described by Verwoerd et al. (1989). Approximately $20-\mu \mathrm{g}$ aliquots of total RNA were loaded onto a denaturing $1 \%$ agarose gel containing 2.2 M formaldehyde. After electrophoresis the RNA was transferred to a blotting membrane (Hybond-N, Amersham, U.K.) and probed with a radiolabeled ORF0 fragment or a radiolabeled rubisco cDNA fragment. This cDNA fragment was synthesized against mRNA isolated from leaves of potato and a kind gift of J. P. H. Nap (DLO Centre for Plant Breeding and Reproduction Research, Wageningen, The Netherlands).

For reverse transcription and subsequent PCR amplification, total plant RNA was isolated with the RNeasy Plant Total RNA Kit (Qiagen, Hilden, Germany) according to the manufacturer's instructions. An oligonucleotide homologous to positions 70 to 89 of the PLRV genome (van der Wilk et al. 1989) was used as $5^{\prime}$ primer and an oligonucleotide complementary to the nucleotides 798 to 812 of the PLRV genome was used as downstream primer.

\section{Analysis of genomic DNA in transgenic potato plants.}

For Southern analysis, genomic DNA was isolated from the plant material as described by Dellaporte et al. (1983). The genomic DNA was digested with restriction enzymes, separated on agarose gel, and subsequently transferred to a blotting membrane (Hybond-N) (Sambrook et al. 1989). The blots were hybridized with a radiolabeled ORF0 probe or rubisco probe.

PCR on genomic DNA was carried out with oligonucleotides identical to a sequence in the CaMV 35S-promoter (92 nucleotides upstream of the start codon of ORF0 in the binary construct) and complementary to the $3^{\prime}$ end of the ORF0.

\section{Analysis of the PLRV p28 protein in transgenic potato plants.}

Transgenic and PLRV-infected plants were analyzed for p28 protein expression with ELISA and Western blot procedures. To analyze the presence of accumulated p28, antisera were used that had been raised against two synthetic peptides (ELISA) and raised against a p28-glutathione-S-transferase (GST) fusion protein produced in Escherichia coli (Western blot). The amino acid sequence of p28 was analyzed with the help of the GCG computer program Peptidestructure (Jameson and Wolf 1988; Devereux et al. 1984). Two domains with a high antigenic index were identified at amino acid positions 64 to 83 and 205 to 224 , respectively. Two synthetic peptides identical to the identified domains were synthesized, with amino acid sequences CKRGRISTSGLQLPRHLHYE (SYN1) and ARLYNQLDLQGRAKSFRALT (SYN2), respectively. The synthetic peptides were covalently conjugated to the carrier protein keyhole limpet haemocyanin $\left(\mathrm{KLH} ; M_{\mathrm{R}}\right.$
$4.5 \times 10^{4}$ to $1.3 \times 10^{7}$ ) utilizing 1-ethyl-3-3-dimethylaminopropyl carbodiimide hydrochloride (EDC) as a coupling reagent. Coupling reactions and subsequent purification of the conjugate were carried out with a commercially available kit (Imject Immunogen EDC Conjugation Kit, Pierce, Rockford, IL) according to the manufacturer's instructions. Rabbits were immunized by two subcutaneous injections at a 3-week-interval with approximately $100 \mu \mathrm{g}$ of conjugate emulsified with equal volumes of Freund's incomplete adjuvant, 3 three weeks later by a subcutaneous booster injection with approximately $200 \mu \mathrm{g}$ conjugated protein. One week after this injection, blood was taken from the rabbits and tested for immunogenic response in ELISA. Gamma-globulin fractions were purified from the serum according to Clark and Adams (1977).

To raise an antiserum suitable in Western blot procedures, the BamHI-equipped ORF0 fragment was ligated in the bacterial expression vector pGEX-2T and the obtained construct (pGEXP28) was used to transform JM101 cells. Cells harboring the plasmid were grown to mid-log phase at $37^{\circ} \mathrm{C}$, after which expression was induced by adding isopropyl-a-Dthiogalactoside (IPTG) to a final concentration of $1.0 \mathrm{mM}$ to the culture. The cells were allowed to grow further for $5 \mathrm{~h}$ and subsequently harvested by centrifugation. To monitor expression of p28, the cells were resuspended in Laemmli buffer (Laemmli 1970) and boiled for $10 \mathrm{~min}$. The samples were loaded onto a $12.5 \%$ sodium dodecyl sulfate (SDS) polyacrylamide gel and subjected to electrophoresis. After electrophoresis the proteins were visualized either with Coomassie brilliant blue or by silver staining. Denatured p28 was isolated from the SDS polyacrylamide gel with a Prep-Cell electrophoresis apparatus (BioRad, Richmond, CA). Purified, denatured protein $(5 \mu \mathrm{g})$ was emulsified in Freund's incomplete adjuvant (Difco, Detroit, MI) and injected four times into two mice at 3 -week intervals. One week after each injection the mice were bled. Gamma-globulin fractions were isolated from the serum by ammonium sulfate precipitation (Clark and Adams 1977).

ELISA was performed as described (van den Heuvel and Peters 1989); transgenic plant tissues were ground in extraction buffer $(0.2 \%$ ovalbumin, $2 \%$ polyvinylpyrrolidone, $0.05 \%$ Tween 20 in phosphate-buffered saline). Two hundred microliters of the suspension was used per well. ELISA plates were coated $(0.5 \mu \mathrm{g} / \mathrm{ml})$ with $\mathrm{IgGs}$ raised against synthetic peptides. IgGs conjugated to alkaline phosphatase were used to detect bound p28. Western blot was carried out with a buffered transfer system. Leaf material or purified protein fractions were ground in Laemmli buffer (Laemmli 1970), boiled for $10 \mathrm{~min}$, and loaded onto a $12.5 \%$ SDS polyacrylamide gel. After electrophoresis, the proteins were transferred to nitrocellulose and probed with antiserum.

\section{LITERATURE CITED}

Ashby, J. W. 1984. Bean leaf roll virus. No. 286 in: Descriptions of Plant Viruses. Commonw. Mycol. Inst./Assoc. Appl. Biol., Kew, England.

Baughman, G. A., Jacobs, J. D., and Howell, S. H. 1988. Cauliflower mosaic virus gene VI produces a symptomatic phenotype in transgenic tobacco plants. Proc. Natl. Acad. Sci. USA 85:733-737.

Bazan, J. F., and Fletterick, R. J. 1989. Comparative analysis of viral cysteine protease structural models. FEBS Lett. 249:5-7.

Brault, V., van den Heuvel, J. F. J. M., Verbeek, M., Ziegler-Graff, V., Reutenauer, A., Herrbach, E., Garaud, J.-C., Guilley, H., Richards, K., and Jonard, G. 1995. Aphid transmission of beet western yellows luteovirus requires the minor capsid read-through protein P74. EMBO 
J. 14:650-659.

Chay, C. A., Gunasinge, U. B., Dinesh-Kumar, S. P., Miller, W. A., and Gray, S. M. 1996. Aphid transmission and systemic plant infection determinants of barley yellow dwarf luteovirus-PAV are contained in the coat protein readthrough domain and 17-kDa protein, respectively. Virology 219:57-65.

Clark, M. F., and Adams, A. N. 1977. Characteristics of the microplate method of enzyme-linked immunosorbent assay for the detection of plant viruses. J. Gen. Viol. 34:475-483.

Dellaporte, S. L., Woods, J., and Hicks, J.B. 1983. A plant DNA minipreparation version II. Plant. Mol. Biol. Rep. 1:19-21.

Deom, C. M., Schubert, K. R., Wolf, S., Holt, C. A., Lucas, W. J., and Beachy, R. N. 1990. Molecular characterization and biological function of the movement protein of tobacco mosaic virus. Proc. Natl. Acad. Sci. USA 87:3284-3288.

Devereux, J., Haeberli, P., and Smithies, O. 1984. A comprehensive set of sequence analysis programmes for the VAX. Nucleic Acids Res. 12:387-395.

Duffus, J. E. 1972. Beet western yellows virus. No. 89 in: Descriptions of Plant Viruses. Commonw. Mycol. Inst./Assoc. Appl. Bio., Kew, England.

Goldberg, K., Kiernan, J., Schoelz, J. E., and Shephard, R .J. 1989. Transgenic host response to gene VI of two caulimoviruses. Pages: 58-66 in: Viral Genes and Plant Pathogenesis. T. P. Pirone and J. G. Shaw, eds. Springer Verlag, New York

Gorbalenya, A. E., Donchenko, A. P., Blinov, V. M., and Koonin, V. E. 1989. Cysteine proteases of positive strand RNA viruses and chymotrypsin-like serine proteases. A distinct protein superfamily with a common structural fold. FEBS Lett. 243:103-114.

Harrison, B. D. 1984. Potato leafroll virus. No. 291 in: Descriptions of Plant Viruses. Commonw. Mycol. Inst./Assoc. Appl. Bio., Kew, England.

Hoekema, A., Huisman, M. J., Molendijk, L., van den Elzen, P. J. M., and Cornelissen, B. J. C. 1989. The genetic engineering of two commercial potato cultivars for resistance to potato virus X. Bio/Technology 7:273-278.

Ingham, D. J., and Lazarowitz, S. G. 1993. A single missense mutation in the BR1 movement protein alters the host range of the squash leaf curl geminivirus. Virology 196:694-702.

Jameson, B., Wolf, H. 1988. CABIOS 4:181-186.

Keese, P., Martin, R. R., Kawchuk, L. M., Waterhouse, P. M., and Gerlach, W. L. 1990. Nucleotide sequences of an Australian and a Canadian isolate of potato leafroll luteovirus and their relationships with two European isolates. J. Gen. Virol. 71:719-724.

Koonin, E. V. 1991. The phylogeny of RNA-dependent RNA polymerases of positive-strand RNA viruses. J. Gen. Virol. 72:2197-2206.

Laemmli, U. K. 1970. Cleavage of structural proteins during assembly of the head of bacteriophage T4. Nature 277:680-685.

Lazarowitz, S. G. 1991. Molecular characterization of two bipartite geminiviruses causing squash leaf curl disease: role of viral replication and movement functions in determining host range. Virology 180:70-80

Linn, F., Heidmann, I., Saedler, H., and Meyer, P. 1990. Epigenetic changes in the expression of the maize A1 gene in Petunia hybrida: Role of numbers of integrated gene copies and state of methylation. Mol. Gen. Genet. 222:239-336.

Martin, M. T., and Garcia, J. A. 1991. Plum pox potyvirus RNA replication in a crude membrane fraction from infected Nicotiana clevelandii leaves. J. Gen. Virol. 72:785-790.
Mayo, M. A., Robinson, D. J., Jolly, C. A., and Hymann, L. 1989. Nucleotide sequence of potato leafroll virus RNA. J. Gen. Virol. 70: 1037-1051.

Pascal, E., Goodlove, P. E., Wu, C. L., and Lazarowitz, S. G. 1993. Transgenic tobacco plants expressing the geminivirus BL1 protein exhibit symptoms of viral disease. Plant Cell 5:795-807.

Razin, A., and Cedar, H. 1991. DNA methylation and expression. Microbiol. Rev. 55:451-458.

Rochow, W. F. 1970. Barley yellow dwarf virus. No. 32 in: Descriptions of Plant Viruses. Commonw. Mycol. Inst./Assoc. Appl. Biol., Kew, England.

Sambrook, J., Fritsch, E. F., and Maniatis, T. A. 1989. Molecular Cloning: A Laboratory Manual. 2nd ed. Cold Spring Harbor Laboratory, Cold Spring Harbor, New York.

Scheid, M. O., Paszkowski, J., and Potrykus, I. 1991. Reversible inactivation of a transgene in Arabidopsis thaliana. Mol. Gen. Genet. 228:104-112.

Scholthof, H. B., Scholthof, K.-B. G., and Jackson, A. O. 1995a. Identification of tomato bushy stunt virus host-specific symptom determinants by expression of individual genes from a potato virus $\mathrm{X}$ vector. Plant Cell 7:1157-1172.

Scholthof, H. B., Scholthof, K.-B. G., Kikkert, M., and Jackson, A. O. 1995b. Tomato bushy stunt virus spread is regulated by two nested genes that function in cell-to-cell movement and host-dependent systemic invasion. Virology 213:425-438.

Tacke, E., Prufer, D., Schmitz, J., and Rohde, W. 1991. Characterization of a potato leafroll luteovirus subgenomic RNA: The $17 \mathrm{~K}$ protein is a single-stranded nucleic acid-binding protein. J. Gen. Virol. 72:20352038.

Tacke, E., Schmitz, J., Prufer, D., and Rohde, W. 1993. Mutational analysis of the nucleic acid-binding $17 \mathrm{kDa}$ phosphoprotein of potato leafroll luteovirus identifies an amphiphatic $\alpha$-helix as the domain for protein/protein interactions. Virology 197:274-282.

van Blokland, R., van der Geest, N., Mol, J. N. M., and Kooter, J. M. 1994. Transgene-mediated suppression of chalcone synthase expression in Petunia hybrida results from an increase in RNA turnover. Plant J. 6:861-877.

van den Heuvel, J. F. J. M., and Peters, D. 1989. Improved detection of potato leafroll virus in plant material and in aphids. Phytopathology 79:963-967.

van der Wilk, F., Huisman, M. J., Cornelissen, B. J. C., Huttinga, H., and Goldbach, R. 1989. Nucleotide sequence and organization of potato leafroll virus genomic RNA. FEBS Lett. 245:51-56.

Veidt, I., Bouzoubaa, S. E., Leiser, R.-M., Ziegler-Graff, V., Guilley, H., Richards, K., and Jonard, G. 1992. Synthesis of full-length transcripts of beet western yellows virus RNA: messenger properties and biological activity in protoplasts. Virology 186:192-200.

Veidt, I., Lot, H., Leiser, M., Scheidecker, D., Guilley, H., Richards, K., and Jonard, G. 1988. Nucleotide sequence of beet western yellows RNA. Nucleic Acids Res. 16:9917-9932.

Verwoerd, T. C., Dekker, B. M., and Hoekema, A. 1989. A small-scale procedure for the rapid isolation of plant RNAs. Nucleic Acids Res. $17: 2362$

Ziegler-Graff, V., Brault, V., Mutterer, J. D., Simonis, M.-T., Herrbach, E., Guilley, H., Richards, K. E., and Jonard, G. 1996. The coat protein of beet western yellows luteovirus is essential for systemic infection but the viral gene products P29 and P19 are dispensable for systemic infection and aphid transmission. Mol. Plant-Microbe Interact. 9:50151. 